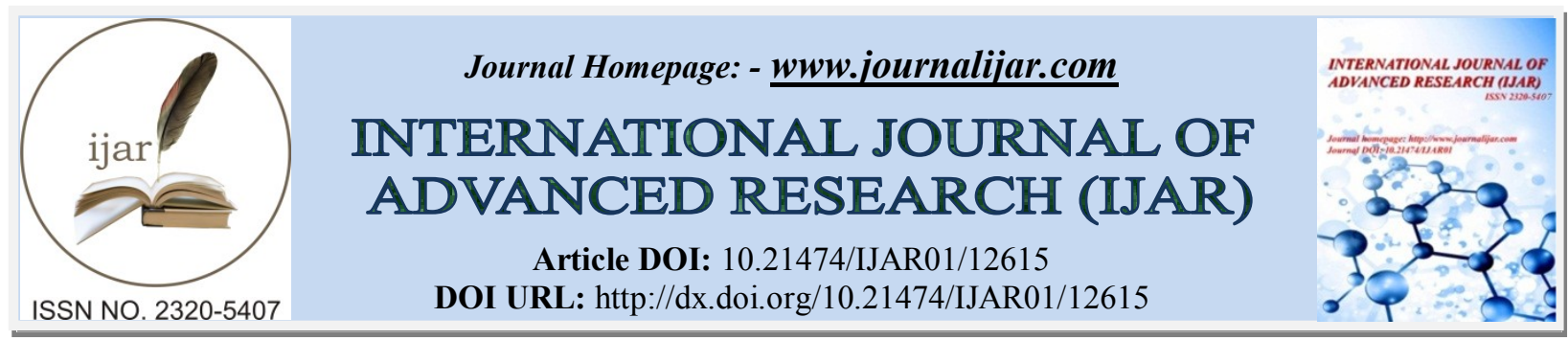

RESEARCH ARTICLE

\title{
MANAGING CHILD IN DENTAL OFFICE BY NON-PHARMACOLOGICAL BEHAVIOR MANAGEMENT TECHNIQUES
}

\section{Dr. Layeeque Ahmad ${ }^{1}$, Dr. Deepti Jawa ${ }^{2}$, Dr. Rani Somani ${ }^{3}$, Dr. Shipra Jaidka ${ }^{2}$, Dr. Arwah Bashir ${ }^{1}$, Dr. Imtiyaz Magray $^{4}$, Dr. Muhamed Sabin $\mathrm{AP}^{1}$, Dr. Aiswarya $^{1}$ and Dr. Payel Basu ${ }^{1}$}

1. Post Graduate Student, Department of Pediatric and Preventive Dentistry, Divya Jyoti College of Dental Sciences and Research Centre, Ghaziabad, Uttar Pradesh, India.

2. Professor, Department of Pediatric and Preventive Dentistry, Divya Jyoti College of Dental Sciences and Research Centre, Ghaziabad, Uttar Pradesh, India.

3. Professor and Head of the Department, Department of Pediatric and Preventive Dentistry, Divya Jyoti College of Dental Sciences and Research Centre, Ghaziabad, Uttar Pradesh, India.

4. Lecturer, Department of Prosthodontics, Crown \& Bridge, Government Dental College \& Hospital, Srinagar, $\mathrm{J} \& \mathrm{~K}$, India.

\section{Manuscript Info}

\section{Manuscript History}

Received: 20 January 2021

Final Accepted: 24 February 2021

Published: March 2021

Key words:-

Behaviour Management, Anxiety,

Attitude, Authoritarian, Desensitization,

Distraction, Hypnosis

\section{Abstract}

Behaviour management of a child in the dental office refers to methods of obtaining a child's approval of treatment in the dental chair which is based on proper communication, patient/ parent education with empathy, coaching and listening. The concept behind guiding a child's behaviour is treating them rather than just operating the tooth alone. The outcome of these techniques could maintain a proper communication or extinguish disruptive behaviour related to dental treatment.

Copy Right, IJAR, 2021,. All rights reserved.

\section{Introduction:-}

Kids are benevolent creatures of God and moreover they are the keys to the future. Hence more long-lasting beneficial effects can result when the seeds for future dental health are planted early in life. From the moment of child's birth, parents shape their children's behaviors by selective encouragement and discouragement of particular behaviors, disciplinary techniques etc. The foundation of practicing dentistry for children is the ability to guide them through their dental experiences. In 1895 McElroy wrote, "Although the operative dentistry may be perfect, the appointment is a failure if the child departs in tears". ${ }^{1]}$

Behavioral dentistry is an interdisciplinary science. The objective of the science is to develop in a dental practitioner an understanding of the interpersonal social force that influences a patient's behavior. Fear of dentistry is common both in adults and in children. Amongst children, dental anxiety may manifest as disruptive or non-compliant behavior. It has been estimated that $13 \%$ of children show reluctance to attend their first dental treatment, and $11 \%$ react negatively during the treatment. ${ }^{[2]}$ Management of the dentally anxious patient is challenging for the dental practitioner. Patients avoid making dental visits because of their fear, which results in a worsening of problems, requiring more intensive and potentially traumatic treatment, which when reinforced exacerbates the fear and becomes a vicious cycle, often leading to poorer dental health. So it is important to deliver a positive dental attitude 
along with quality care for better outcome. A fearless experiences giving comfort, relief and solace are some of the factors justifying the successful outcome of pediatric dentistry.

"Behaviour modification is defined as the attempt to alter human behaviour and emotion in a beneficial manner according to the laws of modern learning (Eysenck, 1964)". ${ }^{[3]}$ In providing oral health care for infants, children, adolescents, and persons with special health care needs, a continuum of both non-pharmacological and pharmacological behavior guidance techniques may be used. A child's behaviour pattern in any situation is governed by his inherited physical and mental endowment, and as he develops, by the conditioning he receives through contact with his environment. Whether children accept dental treatment gracefully, or refuse it will entirely depend on how they have been conditioned. A study of the sciences which help understand the development of fears, anxieties and anger as it applies to the child in the dental situation can be designated as Behavioral Pedodontics.

The American Academy of Pediatric Dentistry (AAPD, 1997) has outlined ten behavior management methods for use with children like: voice control; tell-show-do; positive reinforcement; distraction; non-verbal communication; hand over mouth technique; physical restraint; conscious sedation; nitrous oxide; general anesthesia. ${ }^{[4]}$

Factors Affecting The Child's Behaviour In The Dental Office:

Successful dentistry not only depends upon the dentist's skills but also upon its ability to acquire and maintain child's cooperation to manage children with non-cooperative and disruptive behaviour in the dental clinic. Lack of cooperation in a child not only affects the completion of the treatment and the quality of necessary dental procedures but also raises some degree of stress in the dentist. There are many factors which can influence the behaviour of children in the dental situation. ${ }^{[5]}$

\section{Anxiety:}

It is a normal response that is necessary in many situations in order to feel safe and secure for an individual (Chambers DW 1970). Though anxiety develops from fear; it may be objective or subjective fear. ${ }^{[6]}$

\section{Objective fear:}

Fears that are directly induced by the dentists to the patients by improperly handling them and leaving a bad impression for future dental treatment.

\section{Subjective fear:}

Fears which a child has instilled because of others about their unpleasant experiences, without a child himself/herself experiencing it. It is more intense as they are more easily magnified by a child's imagination.

\section{Crying In The Dental Clinic:}

There are four types of children cries (Elsbach et al 1963) ${ }^{[7]}$.

\section{Obstinate cry:}

Child who "throws a temper tantrum" to prevent dental treatment. The cry is louder, high pitched and moreover it is defined as "Siren-like wail.The child is also known for their belligerent behavior

\section{Frightened cry:}

This type of child is usually noticed with a "torrent of tears" and convulsive, breath catching sobs. The Dentist's responsibilities are to instill positive attitude in the child by providing a series of careful dental procedures.

\section{Hurt cry:}

It is accompanied by a small whimper which can be a loud. The first indication of their discomfort can be noticed by single tear welling at corner of the eye and running down the child's cheek. They can be easily identified by their voluntarily action or when asked, that he is being hurt and the dentist should stop the procedure immediately and pain have to be relieved.

\section{Compensatory cry:}

This type of cry is not really a cry at all. The sound is usually a "droning monotone" which can irritate the dentist. The dentist should understand the compensatory cry as the strategy the child has developed to overcome his anxiety and 
the dentist should not do anything to stop it.

Children's Attitudes Towards Dentistry:

Attitude can be defined as "a readiness, inclination or tendency to act toward inner or external elements in accordance with the individual's acquaintance with them" (Crow et al; 1953). ${ }^{[8]}$ Many investigators have believed that the attitude of children from preschool through elementary level are positive in consider to dentistry. Various factors influence the child's behavior in dental situations, which can be catogorised as:

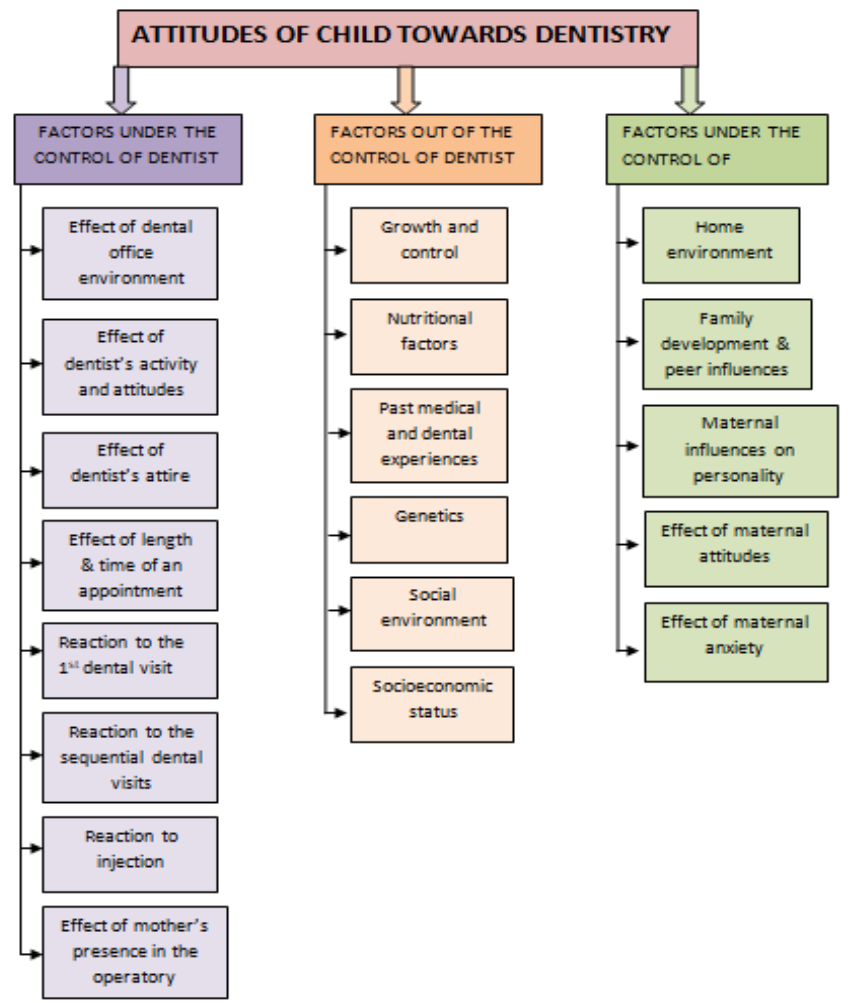

Flowchart 1:- Factors influencing child's behaviour in dental operatory.

\section{Factors Under The Control Of Dentist:}

The management of children with non-cooperative and disruptive behaviour in the dental clinic continues to be a major challenge to the dental practitioners. Most children strive to be cooperative; in these situations the dentist should support the child's behaviour. When a child is uncooperative, his behavior must be altered and controlled. There are many factors which a dentist can modify to help the child through the dental appointments.

\section{Effect of dental office environment:-}

Dental clinic environment should be warm and homely. A pleasant environment helps to establish healthy communication with the child. The operating environment should be made colorful and lively with posters, TV and videogames, toys, story books and comics. Dental auxiliary should be kind to the children and should greet them with a smile; for example- awarding a child with their favorite toys, tattoos, drawing paints etc. for catching their attentions towards the dental clinics and procedures. The appointment time should always be short, i.e., less than 30 minutes. Early morning appointments are preferable for younger children and they should not be kept waiting for too long in the waiting area because they tend to become restless. So the appointment should be scheduled carefully. ${ }^{[9]}$

\section{Effect of dentist's activity and attitude:}

A dentist's attitude can support a child in their attempt to establish proper behaviour. Jenks (1964) described six categories of activities by which dentists can enhance cooperative behaviour in children. These activities are as follows: ${ }^{[10]}$ 


\section{Data gathering and observation:}

It involves collecting the type of information about a child and his/her parents that can be obtained by a formal or informal office interview or by a written questionnaire. Observation involves perceiving overt and subtle behavioral characteristics of a child which provide clues as to how he should be approached by the dentist and his staff. Observation begins with noting the waiting room behaviour of the child, including the interaction with the parent. Observation should be a continuous activity. At each appointment, the dentist should be prepared to modify their approach to a child as the child's behaviour changes and/or as the dentist's perception if it is changed.

\section{Structuring:}

Structuring refers to the establishment of guidelines of behaviour which are communicated by the dentist to the child. With proper structuring, children should know what to expect and how to react during the dental experience. Jenks describes several ways in which the dentist may provide structure to the dental appointment. The dentist should explain to the child, in language that the child can understand, the purpose to the dental treatment. Example: Use of a second language (Euphemisms). Euphemisms are terminologies which are used for making the children cooperative during dental procedures. The different terminologies given in this context are as follows (table 1).

\begin{tabular}{|l|l|}
\hline Dental Terminology & Word Substitute \\
\hline Mouth mirror & Tooth mirror \\
\hline Probe/Explorer & Tooth counter \\
\hline Caries & Brown spot/Sugar bugs \\
\hline Bur & Brush or pencil \\
\hline Suction & Mouth vacuum cleaner \\
\hline Air syringe & Wind gun \\
\hline Water syringe & Water gun \\
\hline X-ray & Camera \\
\hline Radiograph & Picture \\
\hline Hand piece & Whistling train \\
\hline Anaesthetic & Sleepy medicine or sleepy water \\
\hline Impression material & $\begin{array}{l}\text { Pudding, clay dough for making a mould of the } \\
\text { teeth }\end{array}$ \\
\hline Rubber dam & Rain coat or Halloween mask \\
\hline Rubber damp clamp & Rain coat button \\
\hline Pit and fissure sealant or & Tooth paint or tooth vitamins \\
varnish & \\
\hline
\end{tabular}

Table 1:- Word substitutes used in communication with children.

\section{Externalisation:}

It is a process by which the child's attention is focused away from the sensations associated with the dental treatment. The local Injection procedure is an example of when externalisation is often required. There are two methods of externalising the patient's attention: first, involve them in verbal activity; and second, involve them in the dental activity. Example: by giving the child a hand mirror with which they can observe most of the dental procedure.

\section{Empathy and support:}

It is the capacity to understand and to experience the feelings of another without losing one's objectivity. Dentists must have the sensitivity to respond to children's feelings by allowing children to express their feelings. There are 
ways in which dentists can provide this kind of support include: (i) Permitting children to express their feelings of fear or anger, and their desires, without rejecting them. (ii) Communicating to children that their reactions are understood. (iii) Comforting children when it is appropriate. This can be done by careful choice of words, by the tone of the voice or by touching the child and giving a reassuring pat or hug.

\section{Flexible authority:}

Dentist's authority must be tempered with a degree of flexibility and should be sufficiently flexible to allow him to modify his tactics at the same time or at future visits. The dentist must consider whether the behaviour is due to the child's personality or lack of maturity, or whether he himself has contributed to the situation by his approach to the child.

\section{Education and training:}

Any dentist who treats children should implement a programme that educates children to constitutes good dental health.

\section{Effect of the dentist's attire:}

The attire worn by dentists varies from a surgical gown or white clinic jacket to a shirt and tie or open-necked shirt. The use of child friendly colors as attires may help in reliving dental anxiety and aid in better communication. According to Umamaheshwari et al (2013) ${ }^{[11]}$, Vijaya Prasad et al (2015) ${ }^{[12]}$ and Prashant Babaji et al (2017) ${ }^{[13]}$, where they have concluded that the use of child friendly colours like "yellow" or "blue" in the dental workplace could enhance the positive dental attitude in the child's mind and help to manage the anxious child in a more proper way.

\section{Effect of the length and time of an appointment:}

The earlier dental literature has stressed that appointments for children should be short, possibly because of the short attention span of children. The early morning appointments are preferable for young children because they are more rested and cooperative while in the afternoon they may be tired from missing a nap.

\section{Reactions to the first dental visit:}

The child's first dental visit to the dental office is usually between 3-4 years of age. It has been found that the degree of cooperation is more in preschool children in their first dental visit. Therefore, the first visit should only include an examination, radiographs and possibly an oral prophylaxis along with topical fluoride treatment. ${ }^{[14,15]}$

\section{Factors Out Of The Control Of The Dentist: ${ }^{[16]}$ Growth and development:}

If there is a deficiency in physical growth and development or congenital malformations, e.g., cleft lip, as awareness of the deformity increases it leads to psychological trauma due to rejection by the society. Mental retardation, epilepsy, cerebral palsy etc., make the child mentally handicapped. Here, the child cannot react to the requirements of the mother and expectations of the society. Hence, there is a failure of cognitive development and therefore variations in the behaviour are encountered. Also, a very young child reacts very differently and the same response may be transformed to a positive behaviour, as the child grows older. Thus the intellectual age of 3 years seems to be that point in developmental progress that signifies a maturational readiness to accept dental treatment.

\section{Past medical and dental experiences:}

Any past unpleasant dental experience, prior hospitalization, surgical intervention, sickness etc., are associated with a higher degree of uncooperative behaviour. Therefore the emotional quality of past visits rather than the number of visits is significant. Thus more time should be given to this kind of patient to adapt well to the dental environment.

\section{School environment:}

Fifty per cent of the child's development is affected by the school and the remaining $50 \%$ by the home environment. In school, teachers and peers help to influence the behaviour of the younger children. Also, seniors become role models to the juniors. Thus the regular dental campaign has to perform in the schools to educate the teachers as well as the students and they should be advised not to portray wrong image of the dentist in front of the child. Rather, inform them to give a clear picture of the dental procedure to the child. 


\section{Socioeconomic status:}

High socioeconomic status child may develop normally because the family can provide all the necessary requirements to aid in a normal psychological development because these parents are well educated to know the good or bad of their children. On the other hand, this child may also become spoilt if he always gets what he wants. While a low socioeconomic status child often gets little attention because of less less income and less knowledge of their parents as they were unable to fulfill the needs of their children in a proper manner. It can also directly affect the child's attitude towards the value of the dental health.

\section{Factors Under The Control Of The Parents:}

Home environment:

The home is the first school where a child learns to behave. All the individuals at home influence the child's behaviour but none so much as the mother, e.g., in case of a broken home, the child may feel insecure, inferior, apathic and depressed. Mother-child relationship has been described as one-tailed. Postnatal behaviour of the child depends on the prenatal emotional status of the mother.

\section{Family development and peer influences:}

Position and status of the child in the family and parental attitudes can influence the child's behaviour. Overindulgence by parents can lead to a spoilt behaviour in the child who may show sudden outbursts and temper tantrums. Internal family conflicts affect children's behaviour. The child can sense disharmony in the family and this can emotionally frustrate the child. The younger child always tries to follow the model of the older sibling and family members, thus showing the same behaviour of siblings.

\section{Effect of maternal attitudes:}

Maternal attitudes can adversely affect the child's developing personality (figure 1). ${ }^{[17]}$ It can be sub-grouped as under:

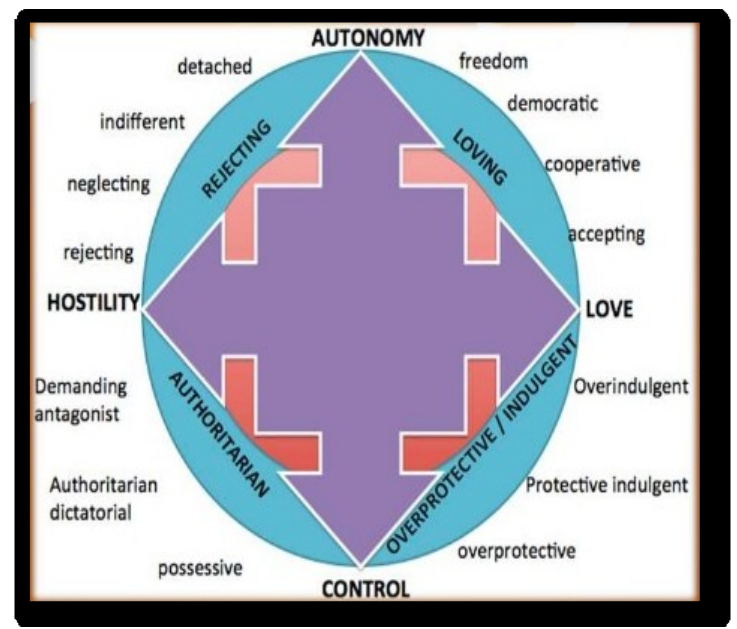

Figure (1):- Maternal attitudes influence the development of children's personalities.

\section{Overprotective mother:}

Mother exhibits extreme love and affection for their children. Possible factors for an overprotective mother: ${ }^{[16]}$

1. History of previous miscarriages.

2. Delay in conception.

3. Death of another sibling.

4. In case of mother cannot have more children.

5. A serious illness to the child.

6. Paternal absence due to death or divorce.

7. Possible signs for an overprotective mother: She gives excessive care to the child in terms of feeding, dressing, bathing.

8. Overprotective mother can affect the normal psychologic maturation of the child and tends to "infantize" him.

9. Dominating overprotective mother exhibits a "submissive child" while overindulgent overprotective mother shows aggressive behavior in the child. These parents should be approached with a gentle discussion of the 
child's actual behavioural ability and the need for the development of independence.

\section{Overindulgent mother:}

This type of mother makes the child spoil by giving them whatever the child needs and so the child expects the same in the dental office. ${ }^{[16]}$

\section{Under affection:}

Mother may feel less emotionally supportive of her child due to her outside interests or due to employment her child. The dentist can find them easily cry, are shy and are unable or unwilling to cooperate. These children can be cooperative if a dentist will give them emotional support or needed affection. ${ }^{[19]}$

\section{Rejection:}

Acceptance vs rejection is one of the most significant of family influences. Maternal rejection may develop due to: Unstable or unhappy marriage life, Unaccepted birth of the child, Child's presence may hinder the mother's carrier, Immature or emotionally unstable mother. Child shows extreme anxiety and can be aggressive, overactive and disobedient. This type of children is difficult to manage and requires regular interval of behavior modifications. ${ }^{[18]}$

\section{Manipulative:}

These parents are demanding type with underlying issues of control and power. They try to direct the course of dental treatment by instructing the dentists. ${ }^{[16]}$

\section{Neglectful:}

These parents may be overly busy, careless, or unappreciative of good dental care. They must be educated about the importance of dental treatment. ${ }^{[16]}$

\section{Hostile:}

The hostile parent may have had a previous poor experience or harbour generally negative attitudes toward health professionals. They may feel insecure and uncomfortable in an unknown environment or may simply have misconceptions about dentistry. ${ }^{[16]}$

\section{Authoritarian:}

This type of parent chooses the technique for child's behaviour, and is termed as "non-love-oriented". Discipline often becomes the form of physical punishment or verbal ridicule for the child. The authoritarian mother is herself the product of authoritarian upbringing. Dawdling and evasive behavior is a characteristic of this type of child.

\section{Effect of maternal anxiety:}

Mothers plays the significant roles in the development of a young child which determine a specific relationship between maternal anxiety and children's behaviour in the dental situation.

Children whose mothers have high anxiety level exhibit more negative and uncooperative behaviour than do children whose mother have low anxiety levels. ${ }^{[19,20]}$

\section{Techniques:}

Dental care for children depends on the child management skills of the dental operator and the team. The various non-pharmacological behavior management techniques are:

\section{Communication:}

Communication is imparting or interchange of thoughts, opinions, or information. For successful communication, all four elements must be present and consistent. ${ }^{[16,17]}$

1. The sender.

2. The message, including the facial expression and body language of the sender.

3. The context or setting in which the message is sent.

4. The receiver.

Communicating with children poses special challenges for the dentist and the dental team. Communication may be impaired when the sender's expression and body language are not consistent. A thorough understanding of the child's cognitive development and vocabulary is important to effectively and efficiently communicate with a child. 
A good communication develops a relationship with a child and a parent, which allows a successful completion of dental procedure. The communication should always start first from the reception area and it can be verbal and nonverbal (flowchart 2).

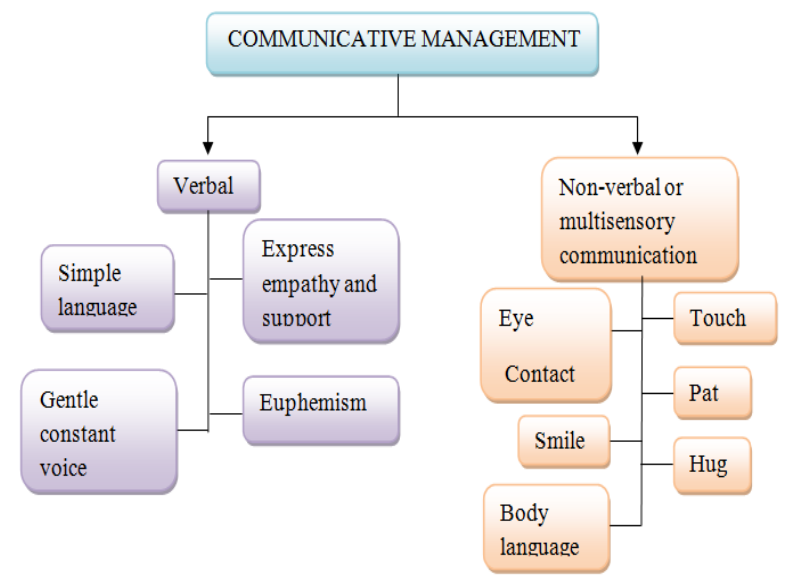

Flowchart (2):- Types of Communicative Management.

\section{Verbal Communication:}

Verbal type of communication is an ideal approach for children more than 3 year of age. The child should be told about the procedure in a clear manner using words that are appropriate to the child's age, so that there is no communication gap between the sender (dentist) and the receiver (child). The basic guidelines for an effective communication are as follows: ${ }^{[21]}$

\section{Establishment of communication:}

It is widely agreed that the first objective in the successful management of a young child is to establish communication. Involving a child in conversation, making them relax and to know more about them should be the first role of a dentist. There are many ways to initiate verbal communication like; what is your name? Do you go to school?

\section{Message clarity:}

The sentenced should be clear, simple and acceptable by the child. The instructions given to the child should be specific and clear like; they should be told that if they will move their body they will get hurt or they should be told to sit still so that the dental procedure will finish faster.

\section{Multisensory communication:}

The spoken word is not the only means of communication. Nonverbal communication, such as stroking the hand of a young child, establishing an eye contact, touching the shoulder can give a young child a feeling of security and promote behavior management.

\section{Problem Ownership:}

Dentist should not say negative things to the child if he is unable to cooperate, like not saying "You are not opening your mouth". Instead he should take the problem ownership on himself and say "I will not be able to work if you do not open your mouth".

\section{Active listening:}

Listening is important in the treatment of all children. This helps in understanding of child's fear or problems. Secondly children's feelings can be acknowledged by: (a) listening quietly, (b) acknowledging the feeling or (c) giving the feeling a name: "Are you really nervous about coming to see me today?

\section{Appropriate responses:}

The dentist should respond to the child in a manner appropriate to the situation. Example: in the first sitting the dentist should not express displeasure over the misbehaviour of child. When the child has undergone treatment a few times and is still not cooperating, then the dentist can express his displeasure and this action of a dentist can be considered as an appropriate response. 


\section{Non-Verbal Communication:}

It is also called Multisensory Communication. When the child enters the operatory, they should be greeted with a smile, handshake and a gentle pat. Even during the treatment, occasional patting or smiling relaxes the child and makes him more obedient. The child is very sensitive to expression changes, so keeping the expression neutral is important. This technique involves a number of psychological components including building trust in the dentistpatient interaction and providing the patient with a sense of control. Thus the technique has been shown to be effective in reducing a patient's experience of anxiety.

\section{Ask tell ask:}

This technique involves inquiring about the patient's visit and feelings toward or about any planned procedures (ask); explaining the procedures through demonstrations (tell); and again inquiring if the patient understands the treatment plan (ask).

\section{Modeling/ Direct Observation:}

It is based on the "observational learning theory" by Bandura given in 1969. Here the child is allowed to see either the live treatment of another child (live modeling) or is shown an audio-visual of child treatment to remove the fear of dental treatment. This helps in removing the fear of dental treatment that is the most common cause for child non -cooperation and treatment refusal. ${ }^{[16,17]}$ (figure 2)

\section{Objectives:-}

To familiarize the patient with the dental settings and specific steps involved in a dental procedure and give the patient and parent an opportunity to ask questions about the dental procedure.

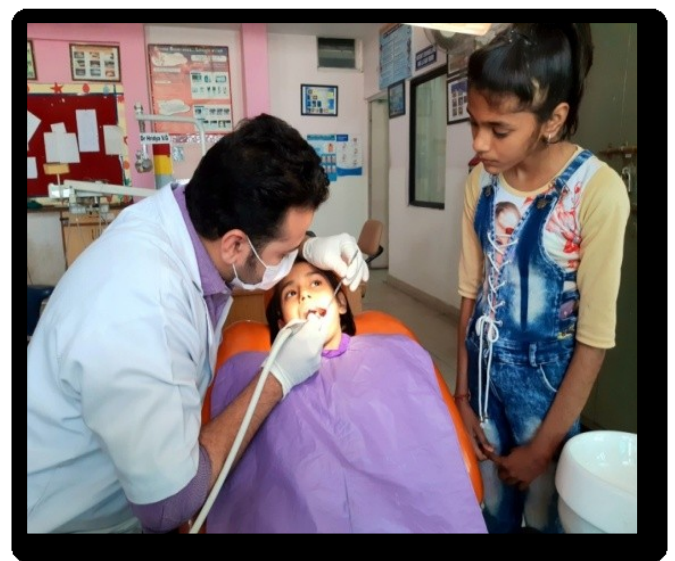

Figure (2):- Patient allowed for directly observing a young cooperative patient undergoing dental treatment.

\section{Tell-Show-Do:}

"Tell show do" technique was given by Addlestone in 1959. It involves verbal explanations of procedures in phrases appropriate to the developmental level of the patient (tell); demonstrations for the patient (show); and then, without deviating from the explanation and demonstration, completion of the procedure (do). The tell-showdo technique is used with communication skills (verbal and nonverbal) and positive reinforcement. ${ }^{[17]}$ (figure 3 )
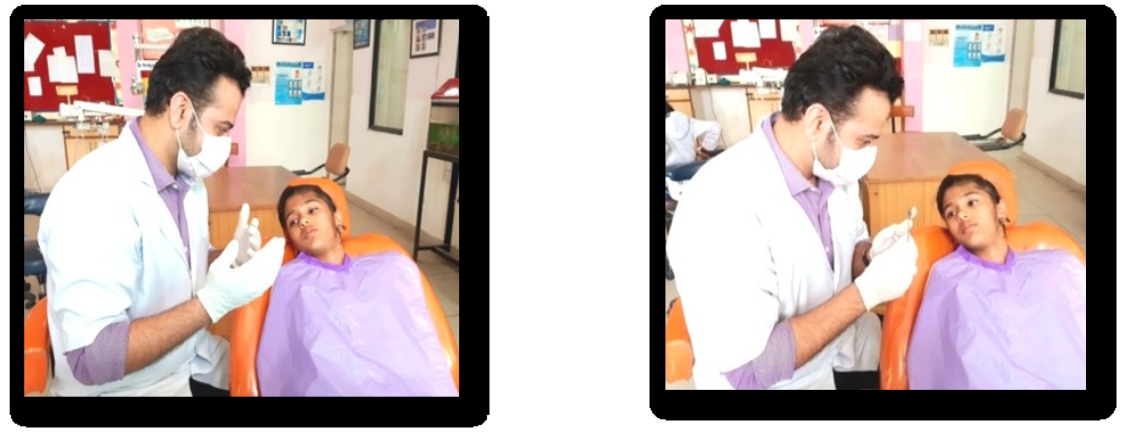
FIGURE 3(a)

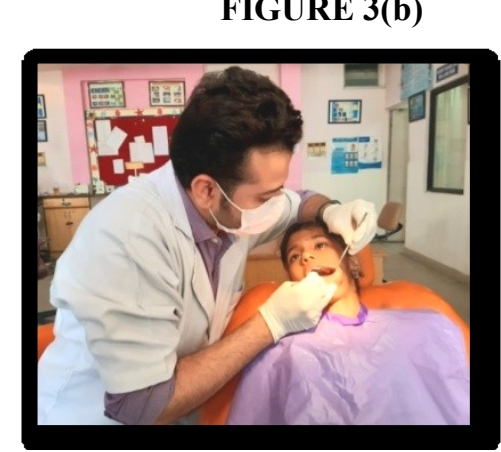

Figure 3(C)

Figure (3):- TELL-SHOW-DO. (a) Verbal explanations of procedures; (b) Demonstration for the patient; (c) Performing the procedure.

\section{Modifications of TELL-SHOW-DO for hearing and visual impaired children: Visually impaired children:}

A "tell, feel, do" technique can be used instead of the "tell, show, do" technique to demonstrate the ongoing procedures to the patient by Mohan R. et al, (2016). He suggested that once the patient becomes familiarized with the sounds, tastes, and smells, treatment should be commenced with short verbal guidance only.

An 'Audio tactile performance technique' (ATP) and multisensory health education method is a very effective communication tool to educate them. ${ }^{[22]}$

\section{Hearing impaired children:}

Technique "Tell-Show-Do" modified into Show-Do and "Hand over Hand" as the best strategy for modeling the desired behavior. The method named as "Do as I do". The training process needs a lot of patience and persistence in order to build proper oral hygiene habits ${ }^{[23]}$

\section{Objectives:-}

The objectives are to teach the patient important aspects of the dental visit and familiarize the patient with the dental setting.

\section{Voice control:}

This technique was given by Pinkham, 1985. The children who are not very cooperative, voice modulation is required. The pitch of voice is slightly raised and with a firm voice, the child is given clear instructions. This technique is very effective in getting the desired behaviour from the willful or resistant child. Even in late infancy and the early toddler years, a sharp, loud, shouted command can be incredibly effective at gaining the child's attention. However when the child obeys the instructions, they should be praised each time.

\section{Objectives:}

To gain the patient's attention and compliance. ${ }^{[17]}$

\section{Retraining/ Desensitization:}

Systematic desensitization was developed by South African psychologist Joseph Wolpe in 1950s. It is one of the most effective methods for reducing maladaptive anxiety. A hierarchy of fear-provoking stimuli should be put together in collaboration with the child or young patient. Once the patient has been taught and learned how to relax, then they should be gradually introduced to the low-to-high fear stimuli at a pace determined by the patient with support from the clinician.

\section{Objectives:}

To help children who had a bad previous medical or dental experience to overcome. ${ }^{[17]}$

\section{Distraction:}

Distraction is the technique of diverting the patient's attention from what may be perceived as an unpleasant 
procedure by allowing them to watch audio- visual cartoons during the treatment or by giving the patient a short break during a stressful procedure can be an effective use of distraction prior to considering more advanced behavior guidance techniques. Example: use of virtual-reality device (VR-box) in the dental operatory during dental procedure.

\section{Objectives:}

To decrease the perception of unpleasantness and avert negative or avoidance behavior.

\section{Parental Presence/Absence:}

The presence or absence of the parent sometimes can be used to gain cooperation for treatment. The parents will expect to be with their infants and young children during examinations as well as during treatment. Parent's desire to be present during their child's treatment does not mean they intellectually distrust the dentist; it might mean they are uncomfortable if they visually cannot verify their child's safety. Practitioners should understand and become accustomed to this added involvement of parents and welcomes the desires and wishes of them.

\section{Objectives:}

\section{The objectives:}

For parents are to participate in infant examinations or treatment and observe the reality of their child's treatment.

For practitioners to gain the patient's attention and improve compliance and enhance effective communication among the dentist, child, and parent. ${ }^{24]}$

\section{Contingency management:}

The presentation or withdrawal of reinforcers is termed as "contingency management".It is based on "Operant Conditioning theory" by BF Skinner, 1938. It is of 4 types:

\section{Positive reinforcement:}

Presentation of a pleasant stimulus to bring about the desired behaviour. Here the child is rewarded for presenting the desired behaviour. Ex: like toy, toothpastes, toothbrushes etc.

\section{Objectives:}

To reinforce desired behavior.

\section{Negative reinforcement:}

Removal of unpleasant stimulus that brings about the desired behaviour. Eg- sight of white apron, facemask, injection or sharp instruments.

\section{Objectives:}

to strengthen the behavior by removing unpleasant stimulu

\section{(a) Omission:}

Removal of pleasant stimulus to bring out the desired behaviour. Eg- if a child is not cooperating in the presence of his parent, then he is told that the parent would be sent outside, if he does not cooperate.

\section{(b) Punishment:}

Presentation of unpleasant stimulus to the child like: hand over mouth technique (HOME) and Protective stabilization. ${ }^{[17]}$

\section{Audio analgesia or white noise:}

The technique consists of providing a sound stimulus of such intensity that the patient finds it difficult to attend to anything else (Morosko et al, 1966). It was introduced by Gardner and Icklider in 1959.

\section{Objectives:}

To reduce the stress or anxiety by providing a sound stimulus. ${ }^{[25]}$ 


\section{Hypnosis:}

Hypnosis seems to be most effective in the presence of anxiety. It was first suggested by Franz A Mesmer in 1773. It is defined as a state of mental relaxation and restricted awareness in which subjects are usually engrossed in their inner experiences such as imagery, are less analytical and logical in their thinking and have enhanced capacity to respond to suggestions in an automatic and dissociated manner.

Uses: Hennon outlined the following uses:

To reduce nervousness and apprehension.

To eliminate defense mechanisms of the patients.

To control functional or psychosomatic gapping. ${ }^{[26]}$

\section{Coping:}

Coping is defined as the cognitive and behavioural efforts made by an individual to master, tolerate or reduce stressful situations by Lazaue, 1980. The normal coping systems followed by the dentists are friendliness, support and reassurance.Coping strategies can be divided into three major categories:

(a) Active coping: The examples of active coping are:

Biofeedback: It is a group of therapeutic procedures that utilizes electronic or electromechanical instruments to accurately measure, process, and "feed back" to person's information.

Music therapy as distraction: Music helps to accomplish individual goals within a therapeutic relationship. ${ }^{[20]}$

Problem solving: Problem solving therapy is a form of cognitive-behavioral therapy that has been shown to be especially useful in the treatment of such disorders as depression and anxiety.

(b) Passive coping: example- distraction by others.

(c) Avoidance: If the person has decided that there is no stressor, and therefore there is no need to change behavior, perception, or emotional response. Example: initially disbelieving that someone has died: "Who died? I can't believe it. I just saw him. ${ }^{[27]}$

\section{Home:}

The technique was introduced by Dr Evangeline Jordan in 1920 who wrote "If a normal child will not listen but continues to cry and struggle - hold a folded napkin over the child's mouth and gently but firmly hold the mouth shut. The purpose of the technique is to gain the attention of a child to allow communication. HOM, although a very effective when used correctly, but is no longer endorsed by the American Academy of Paediatric Dentistry (AAPD) [Guidelines, 2008]. However, many believed hand over mouth was still an acceptable technique by Oueis et al. (2010). ${ }^{[17,28]}$

\section{Techniques:}

When all avenues of communication have failed and the child's behavior remains uncontrolled, HOM is applied. The dentist places their hand to stifle the noise of a child and allow effective communication and at the same time the Dental assistant restraints any flailing limbs.

There is a variation of HOM where the child's airway is deliberately restricted, named hand-over-mouth with airway restriction (HOMAR). The nose is pinched along with the hand over mouth. The child will stop screaming to breathe and the tantrums will decrease. It should not be employed for more than 15 seconds. But this is not accepted as a method universally.

\section{Other Terminologies:}

1. Aversive conditioning by Lenchner and Wright (1975)

2. Emotional surprise therapy by Lampshire

3. Hand over mouth airway restricted (HOMAR) by Levitas (1947)

4. Aversion by Crammer (1973). 


\section{Objectives:}

To gain the child's attention and to stop his verbal outburst.

\section{Indications:}

A healthy child who is able to understand and cooperate but who exhibits defiant behavior.

\section{Contraindications:}

Hand over moth technique is not a technique for the very young.

\section{Protective Stabilization or Restraining:}

Protective stabilization is the restriction of patient's freedom of movement, with or without the patient's permission, to decrease risk of injury while allowing safe completion of treatment. Partial or complete stabilization of the patient sometimes is necessary to protect the patient, practitioner, staff, or the parent from injury while providing dental care. It can be performed by the dentist, staff, or parent with or without the aid of a restrictive device.

\section{Equipments:}

Numerous devices are available to limit movements by a patient unable to cooperate during dental treatment. ${ }^{[17]}$

\section{For limbs:}

1. Posey strap: It contains an ankle and wrist restraint that can be secured with a hook and loop and fastened to the dental chair. It is used to control the hand and legs movement.

2. Posey vest: It is a variant in which the straps are attached to a vest. The patient is made to wear the vest and the straps extending from each corner are tied individually to each side of the chair

\section{For body:}

1. Pedi wrap: It immobilizes the elbow of the patient to prevent the child from getting their hand above the chest level.

2. Papoose board: Papoose boards were originally a wood and leather device used by many Native American tribes to swaddle their infants and children. Papoose board is a device with a flat board and wide fabric straps that can be fastened with Velcro. The child is made lie on the board and the straps were wrapped around the upper body, middle and sometimes legs.

\section{For mouth}

1. Mouth props: A mouth prop is wedge shaped bite block made from a thermoplastic material and used in children who have difficulty in keeping their mouths open wide and steady during dental procedure. They are available in different sizes.

2. Tongue blades: This can be used directly to open a mouth wider. It has a durable foam core on the outside of a tongue depressor and it is easy to use

\section{Objectives: To;}

1. reduce or eliminate unwanted movement.

2. protect patient, staff, dentist, or parent from injury.

3. facilitate delivery of quality dental treatment.

\section{Indications:}

It is indicated in a patient who requires immediate diagnosis, urgent care, and treatment.

\section{Contraindications:}

Patients associated with medical, psychological, or physical conditions.

\section{Precautions:}

The following precautions should be taken:

1. The patient's medical history must be reviewed carefully to ascertain everything is fine.

2. Tightness and duration of the stabilization must be monitored at regular intervals.

3. Stabilization around extremities or the chest must not restrict respiration. 
4. Stabilization should be terminated as soon as possible. ${ }^{[15]}$

\section{Conclusion:-}

Behaviour management is widely agreed to be a key factor in the care of children in paediatric dentistry. Indeed, if a child's behaviour in the dental surgery/office cannot be managed then it is difficult to carry out any dental care that is needed. Behaviour management is therefore one of the corner stones of the speciality. It is important that the knowledge and practice of behaviour management should be incorporated in a continuous learning process or education for all paediatric dentists. ${ }^{[4,7,17]} \mathrm{A}$ wide diversity of behavioral management techniques are existing to pediatric dentists. The American Academy of Pediatric Dentistry (AAPD, 1997) has outlined few nonpharmacological behaviour management techniques like: voice control; tell-show-do; distraction; verbal and nonverbal communication; physical restraint; for providing oral health care for infants, children and adolescents with special health care needs. ${ }^{[17]}$

\section{Refrences:-}

1. Shanthala BM, editor. McDonald and Avery's Dentistry for the Child and Adolescent--E Book: Second South Asia Edition. Elsevier Health Sciences; 2019 Mar 22.

2. Klingberg G, Broberg AG. Dental fear/anxiety and dental behaviour management problems in children and adolescents: a review of prevalence and concomitant psychological factors. International journal of paediatric dentistry. 2007 Nov;17(6):391-406.

3. Burns LE, Worsley JL, editors. Behaviour Therapy in the 1970s: A Collection of Original Papers. Butterworth-Heinemann; 2016 Jul 29.

4. American Academy of Pediatric Dentistry. Behavior guidance for the pediatric dental patient. Pediatr Dent. 2017;39(6):246-59.

5. Sotto JJ, Azari AF, Riley J, Bimstein E. First-year students' perceptions about pediatric dental behavior guidance techniques: the effect of education. Journal of dental education. 2008 Sep 1;72(9):1029-41.

6. Essau CA, Petermann F. Anxiety disorders in children and adolescents: Epidemiology, risk factors and treatment. Routledge; 2013 Jan 11.

7. Chaudhary Navdha,Ahlawat Babita,Kumar Ashok,Ashima,Das Sibadatta. Children's reactions to the dental situation. Journal of pharmaceutical and biomedical sciences (J Pharm Biomed Sci.) 2013 October; 35(35): 1814-1819.

8. Ajzen I. Attitudes, personality, and behavior. McGraw-Hill Education (UK); 2005 Nov.

9. Ripa LW. Attitudinal and environmental influences on children's behavior in the dental situation. In: Ripa LW, Barenie JT, editors. Management of Dental Behavior in Children. Massachusetts: PSG Publication Co; 1979. pp. 27-40.

10. Jenks L. How the dentist's behavior can influence the child's behavior. J. Dent. Child. 1964;31:358-66.

11. Chaudhary N, Ahlawat B, Kumar A. Factors affecting children's behaviour in the dental office. Journal of Pharmaceutical and Biomedical Sciences. 2015 Dec 16;5(12).

12. Umamaheshwari N, Asokan S, Kumaran TS. Child friendly colors in a pediatric dental practice. Journal of Indian Society of Pedodontics and Preventive Dentistry. 2013 Oct 1;31(4):225.

13. Ellore VP, Mohammed M, Taranath M, Ramagoni NK, Kumar V, Gunjalli G. Children and parent's attitude and preferences of dentist's attire in pediatric dental practice. International journal of clinical pediatric dentistry. 2015 May;8(2):102.

14. Babaji P, Chauhan PP, Rathod V, Mhatre S, Paul U, Guram G. Evaluation of child preference for dentist attire and usage of camouflage syringe in reduction of anxiety. European journal of dentistry. 2017 Oct;11(4):531.

15. Alshahrani NF, Alshahrani AN, Alahmari MA, Almanie AM, Alosbi AM, Togoo RA. First dental visit: Age, reason, and experiences of Saudi children. European journal of dentistry. 2018 Oct;12(04):579-84

16. Jain V, Sarkar S, Saha S, Haldar S. Basic behaviour guidance factors and techniques for effective child management in dental clinic-an update review. Int J Oral Health Med Res. 2016;2(6):177-82.

17. American Academy of Pediatric Dentistry. Behavior guidance for the pediatric dental patient. Pediatr Dent. 2017;39(6):246-59.

18. Currie J, Spatz Widom C. Long-term consequences of child abuse and neglect on adult economic well-being. Child maltreatment. 2010 May;15(2):111-20.

19. Wu L, Gao X. Children's dental fear and anxiety: exploring family related factors. BMC oral health. 2018 Dec $1 ; 18(1): 100$.

20. Schaefer ES, Bayley N. Maternal behavior, child behavior, and their intercorrelations from infancy through adolescence. Monographs of the Society for Research in Child Development. 1963 Jan 1:1-27. 
21. Mcdonald and Avery's. Textbook of dentistry for the child and adolescent.9/ed; Elsevier Health Sciences, Apr 2010; page (35-36).

22. Mohan R, Raju R, Gubbihal R, Kousalya PS. Comprehensive dental care for the visually impaired: a review. Int J Oral Health Med Res. 2016;3(4):97-101.

23. Doichinova L, Peneva M. Motivational training programme for oral hygiene of deaf children. Int J Sci Res (Raipur). 2015;4(2):1124-6.

24. Kotsanos N, Arhakis A, Coolidge T. Parental presence versus absence in the dental operatory: a technique to manage the uncooperative child dental patient. European Journal of Paediatric Dentistry. 2005 Sep;6(3):144.

25. Bradt J, Teague A. Music interventions for dental anxiety. Oral diseases. 2018 Apr;24(3):300-6.

26. Bliss EL. Multiple personality, allied disorders, and hypnosis. Oxford University Press, USA; 1986.

27. Sahler OJ, Carr JE. Coping strategies. In Developmental-behavioral pediatrics 2009 Jan 1 (pp. 491-496). WB Saunders.

28. Levitas TC. HOME-hand over mouth exercise. ASDC journal of dentistry for children. 1974;41(3):178. 